only covering the ground of the regular course, but, so far as possible, supplementing this course.

As a relief from mere problem-work in this laboratory exercise, I should strongly recommend the investigation by the class of mathematical fallacies. Many illustrations of these fallacies may be found, of course, in the works devoted to such subjects. DeMorgan and Ball are within reach of most teachers. But it is very easy to invent others, so that the class may be kept constantly on the alert. The detection of the error in a false course of reasoning is quite as good exercise as the solution of the ordinary problem, and while not always as easy, is often more interesting. The laboratory time should be so divided between the subjects that a fairly complete supplementary course may be worked out in each, but that, in any event, the interest of the class should not be allowed to flag.

In all work whether in laboratory or regular class, neatness of form, and accuracy of expression should be absolutely insisted upon. Clarity of thought cannot exist without accuracy of expression, whether oral or written, whether expressed in symbois or diagrams. Harmony and order in ideas should carry with them symmetry and elegance in the expression of those ideas.

( $T o$ be continued)

\title{
BOYLE'S LAW.
}

By C. D. Carpenter, Michigan State Normal College.

The fact that the product of the volume of a given mass of gas, at a constant temperature, and the pressure under which it is placed is a constant, is known as Boyle's or Mariotte's law. It seems that Robert Boyle of England formulated the law in 1662 , and Mariotte of France, without any knowledge of Boyle's discovery verified the same law in 1676 . Thus in France it is known as Mariotte's law.

Nearly every pupil knows that a gas varies in volume according as there is a greater or less pressure upon it; but he does not. know that there is a definite relation existing between the amount of pressure applied and the volume of the gas until he encounters the law just stated. For the proof of this law many pieces of apparatus have been made, simple in operation and 
fairly accurate. It is my purpose to present an apparatus simple in form and differing little from some pieces already in use, but perhaps with some merit which will be brought out in a description of it and an explanation of its use.*

The apparatus is a $U$ shaped tube, with a long and a short arm as shown in Fig. I. It is similar to the J shaped one in common use, differing in that the short arm is about $90 \mathrm{~cm}$ long with a glass stopcock $\mathrm{C}$ at the end while the long arm about I5O $\mathrm{cm}$ long opens with a small funnel into which mercury may be poured. Near the end of the iong. arm is a stopcock $D$ by which the mercury may be drawn off. The extra length of the short arm enables the instrument to be used as a barometer. With the stopcocks $C$ and $D$, the volume of the gas and the height of the mercury may be easily adjusted. The heights of the mercury columns are read by moving the detachable slide up or down on the graduated stick E. The

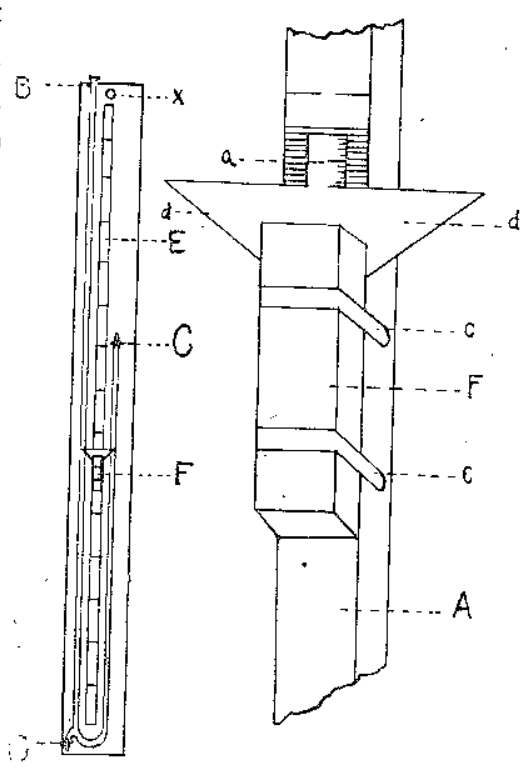

Fig.I
Fig. II

glass tube and graduated stick are mounted upon a base $\sigma_{4}$ inches long as shown in the figure. The instrument may be supported by a hole at the top or it may be fastened permanently by means of screws. The slide F, as shown in Fig. II, mounted upon the scale stick $\mathrm{A}$, has two arms $\mathrm{d}$, d, made of brass, which extend over the glass tubes and may be made with a vernier attachment as indicated at a. The slide is held in place by clips $c$, c, made of spring brass.

In experimenting the stopcock $D$ is closed and the one at $C$ opened. Mercury is then poured in at $\mathrm{B}$ until it rises on the level in both arms just above $\mathrm{C}$. $\mathrm{C}$ is then closed and by opening $\mathrm{D}$ mercury is drawn off until it begins to come away from $\mathrm{C}$.

*The instrument was made in the laboratory at the Michigan State Normal College and tested giving very satisfactory results. In making the instrument aid was given by the pro-
fessors in the department-Professors Strong, Peet, and Gorton. 
The heights of the mercury in the tubes are then taken and the difference recorded as the reading of the barometer. If air is the gas used the stopcock $\mathrm{C}$ is then opened and mercury added or drawn off until the desired air column is obtained. C is again closed. If the original air column is about $30 \mathrm{~cm}$ then readings may be taken for air under pressure of more or less than one atmosphere. Mercury is then poured into the tube at B until full and the height of the mercury in each arm noted. Mercury may then be drawn off a little at a time by means of stopcock $D$ and several readings made.

From the readings the following data may be found. The sum of the barometer reading and the height of the mercury in the long arm minus the height of the mercury in the short arm may always be used as the pressure, while the length of the short arm minus the height of mercury in it may always be regarded as the volume of the gas. Then if,

$\mathrm{H}=$ Height of mercury in the long arm

$\mathrm{H}^{\prime}=$ Height of merctury in the short arm

$\mathrm{B}=$ Barometer reading

$\mathrm{L}=$ The length of the short arm

$$
\begin{aligned}
& \text { Pressure }(\mathrm{P})=\mathrm{B}+\mathrm{H}-\mathrm{H}^{\prime} \\
& \text { Volume }(\mathrm{V})=\mathrm{L}-\mathrm{H}^{\prime}
\end{aligned}
$$

and $\mathrm{P} \times \mathrm{V}=\mathrm{a}$ constant. Results may be recorded as follows:

Barometer Reading 75.

\begin{tabular}{r|c|c|c|c|c}
\hline \multicolumn{1}{c|}{} & Pressure & Volume & Constant \\
\hline $\mathrm{H}$ & $\mathrm{H}^{\prime}$ & $\mathrm{L}$ & $\mathrm{B}+\mathrm{H}-\mathrm{H}^{\prime}$ & $\mathrm{L}-\mathrm{H}^{\prime}$ & $\left(\mathrm{B}+\mathrm{H}-\mathrm{H}^{\prime}\right)\left(\mathrm{L}-\mathrm{H}^{\prime}\right)$ \\
\hline 150 & 75 & 90 & $75+150-75$ & $90-75$ & $150 \times 15=2250$ \\
60 & 60 & 90 & $75+60-60$ & $90-60$ & $75 \times 30=2250$ \\
10 & 40 & 90 & $75+10-40$ & $90-40$ & $45 \times 50=2250$ \\
\hline
\end{tabular}

The same precautions as to pureness and dryness of the mercury and gas used must be taken as in any other instrument.

The instrument being made of glass, saves the contamination of the mercury by metallic or rubber connections.

With proper precautions very good results may be obtained. 